\title{
Effects of Shoulder Abduction on Muscle Activities During Pilates Breathing
}

\author{
Moon-Jeoung Kim, PT, PhD • Sung-Hyun Park, PT, MSc ${ }^{\dagger} \cdot \|-H u n$ Baek, PT, MSc \\ Depart. of Physical Therapy, Graduate School, Catholic University of Pusan \\ ${ }^{1}$ Depart. of Physical Therapy, Dong-Eui Institute of Technology
}

Received: January 15, 2018 / Revised: January 17, 2018 / Accepted: February 8, 2018

(C) 2018 J Korean Soc Phys Med

\section{| Abstract |}

PURPOSE: This Study compared the level of activation of the muscles around the shoulder at the time of abduction through Pilates breathing and regular breathing by using quantified biofeedback.

METHODS: Experiment was conducted on 25 healthy males and females in the age bracket of 20's 30's as the subjects. The level of activation of muscles displayed at the time of Pilates breathing were measured at intercostal ( $\mathrm{InC})$ muscle, transverse abdominis ( $\operatorname{TrA}$ ) muscle, internal oblique (IO) muscle and external oblique (EO) muscle by using surface electromyogram (EMG) and were provided as biofeedback. Moreover, the changes in the level of muscular activation at sternocleidomastoid (SCM) muscle, upper trapezius (UT) muscle and Deltoid (Del) muscle, which are the muscles around the shoulder, at the time of abduction of shoulder during Pilates breathing and regular breathing were measured.

$†$ Corresponding Author : SungHyun Park

nongkuman@hanmail.net, http://orcid.org/0000-0003-3142-9857

This is an Open Access article distributed under the terms of the Creative Commons Attribution Non-Commercial License (http://creativecommons.org/licenses/by-nc/3.0) which permits unrestricted non-commercial use, distribution, and reproduction in any medium, provided the original work is properly cited.
RESULTS: When abduction of shoulder is executed through Pilates breathing, the level of muscular activation of UT muscle was $11.56 \pm 7.10 \%$ at the time of exhaling of Pilates breathing and $17.54 \pm 9.57 \%$ at the time of exhaling of regular breathing. Del muscle also displayed lowered level of muscular activation at the time of Pilates breathing with $12.88 \pm 5.80 \%$ during inhaling and $15.14 \pm 5.49 \%$ during exhaling.

CONCLUSION: In conclusion, the results could be interpreted as indicating that the muscle activities of upper trapezius and deltoid muscle were decreased based on Pilates breathing more than those on regular breathing.

Key Words: Breathing, Electromyography, Pilates

\section{Introduction}

Pilates is one of the exercise methods used widely by people who strive to enhance their physical fitness or lead a healthy life (Anderson, 2000). Pilates is characterized by its ability to enhance the flexibility of the body and strengthen the muscles through balanced postures as well as make the body suppler (Siler, 2000). Therefore, Pilates not only has function as simple exercise but also used widely in an extensive range of domains including treatment 
of diseases of the musculoskeletal system or rehabilitation program (La Touche et al., 2008). Pilates is one of exercise methods in which breathing is a very important factor. Pilates is an exercise method that induces movements by using the principles of centralization, concentration, control, flow, cognition and breathing with focus on controlling the position and movement of the human body (Penelope, 2002). In particular, it assists each of the joints and muscles that surround the trunk to perform their respective functions properly by activating and stabilizing the localized muscles (Endleman and Critchley, 2008; Marques et al., 2013). In Pilates, the trunk is referred to as the powerhouse, core or center (Friedman et al., 1980; Gallagher and Kryzanowska, 1999) and includes the area from the lower ribs to the pelvic base (Latey, 2001; Siler, 2000). This area is composed of the thoracolumbar and pelvis, which are passive elements, and the trunk muscles, which are active elements. These constituent elements provide stability of the trunk and induce the functional movement of the body by forming a mutually supplementary relationship through neuromuscular control (Panjabi, 1992). Various methods are used to elevate such activation of the trunk and the method of using breathing among these is reported to be highly useful (Kim, 2006; Kwon et al., 2016; Park et al., 2007). Ishida et al. (2012) reported that activation of the abdominal muscles increased by inducing the contraction of the lateral aspects of the abdomen through the maximum exhalation (Ishida et al., 2012). Merrick et al. (1981) reported that maintaining the overall contraction of the abdomen through inhalation is helpful in enduring the load during exercise (Merrick et al., 1981). The method of inducing enhancement of the stability of the trunk by using breathing is used importantly in Pilates. Barbosa et al. (2015) reported that Pilates breathing provides stability at when bending the trunk by increasing the activation of TrA and EO (Barbosa et al., 2015). In addition, it was reported that the actions of pulling the abdominal muscles, which is maintained through breathing when doing Pilates movements, affect the activation of not only the TrA but also the bottom muscles of the pelvis (Keays et al., 2008). Moreover, Mateus et al. (2016), as the result of having applied Pilates using breathing to 16 subjects over a period of 8 weeks, confirmed that breathing muscles and abdominal muscles were activated (Mateus et al., 2016). However, the existing researches do not provide accurate values of Pilates breathing executed at the time of Pilates movements. It is only known that the movements are executed by inducing the contraction of the abdominal muscles through inhalation and exhalation (Penelope, 2002). Therefore, this Study compared the level of activation of the muscles around the shoulder at the time of abduction through Pilates breathing and regular breathing by using quantified biofeedback.

\section{Methods}

\section{Subject}

This Study executed an experiment on 25 healthy males and females in their 20's $\sim 30$ 's who consented to participate in the experiment voluntarily after having been given explanations on the purposes and methods of the experiment as subjects over a period of 2 weeks. Subjects with a medical history of having suffered a breathing related disorder or currently suffering from a severe breathing related disorder were excluded. Physical characteristics of the subjects are as follows (Table. 1).

Table 1. Characteristics of study participants $(n=25)$

\begin{tabular}{cc}
\hline & Group $(\mathrm{n}=25)$ \\
\hline Gender (male:female) & $10: 15$ \\
Age & $22.76 \pm 3.52$ \\
Height & $166.4 \pm 7.21$ \\
Weight & $58.44 \pm 10.37$ \\
\hline
\end{tabular}

Values are presented as number or mean \pm standard deviation. 
Table 2. The attachment area of the electrode and the measurement posture

\begin{tabular}{|c|c|c|}
\hline & Electrode & Posture \\
\hline SCM & $\begin{array}{l}\text { Midpoint between mastoid process and depression } \\
\text { in upper sternum }\end{array}$ & $\begin{array}{l}\text { Take measurement at the time of maximum resistance } \\
\text { during the movement of lifting the head by the subject } \\
\text { on the examination table by rotating the head to one } \\
\text { direction while lying down straight on the examination } \\
\text { table }\end{array}$ \\
\hline UT & Midpoint between $\mathrm{C} 7$ and the peak & $\begin{array}{l}\text { Take measurement at the time of maximum resistance } \\
\text { during the movement of lifting the shoulder towards } \\
\text { the ears by the subject }\end{array}$ \\
\hline $\operatorname{Del}(\mathrm{mid})$ & $3 \mathrm{~cm}$ below the outer acromion of the upper arm & $\begin{array}{l}\text { Take measurement at the time of maximum resistance } \\
\text { during the movement of lifting the arm sideways to } \\
\text { the shoulder height by the subject }\end{array}$ \\
\hline $\mathrm{InC}$ & $\begin{array}{l}\text { Space between the } 4^{\text {th }} \text { and the } 5^{\text {th }} \text { ribs at the midline } \\
\text { of clavicle }\end{array}$ & $\begin{array}{l}\text { Take measurement after having instructed the subject } \\
\text { to maximally inhale and then exhale prior to maintain } \\
\text { the exhaled state }\end{array}$ \\
\hline IO & $\begin{array}{l}\text { Area that is parallel with the belly button at the } \\
\text { position approximately } 450 \text { above at the upper frontal } \\
\text { hip bone spine }\end{array}$ & $\begin{array}{l}\text { Take measurement at the time of maximum resistance } \\
\text { during the movement of lifting the upper body with } \\
\text { the left shoulder moving towards the right pelvis while } \\
\text { putting both arms in front of the chest in the posture } \\
\text { of having bent the knees }\end{array}$ \\
\hline EO & $\begin{array}{l}2 \mathrm{~cm} \text { in parallel towards lower and inner direction } \\
\text { at the upper frontal hip bone spine }\end{array}$ & $\begin{array}{l}\text { Take measurement at the time of maximum resistance } \\
\text { during the movement of bending and rotating the trunk } \\
\text { to one direction while having both arms crossed on } \\
\text { the chest by the subject }\end{array}$ \\
\hline $\operatorname{TrA}$ & $\begin{array}{l}2 \mathrm{~cm} \text { below the inner aspect of the upper frontal } \\
\text { hip bone spine }\end{array}$ & Same posture as IO \\
\hline
\end{tabular}

SCM : sternocleidomastoid, UT : Upper Trapezius, Del (mid) : Deltoid-middle part, InC : Intercostal, IO: internal oblique, EO: external oblique, TrA : transvers abdominis.

\section{Experimental Method}

This Study compared the level of activation of the muscles around the shoulder at the time of abduction through Pilates breathing and regular breathing by using surface EMG. Training on Pilates breathing was executed prior to the experiment and the activation of muscles involved in the trunk exercise and posture maintenance used at the time of Pilates breathing was examined. This was provided as biofeedback for proper Pilates breathing. Subjects executed abduction of the shoulder by wearing a $2 \mathrm{~kg}$ sandbag while maintaining Pilates breathing by using biofeedback. It was repeated 10 times over a period of
8 seconds of inhaling and 8 seconds of exhaling at the time of abduction of the shoulder. This was also executed in the same manner for regular breathing. Surface EMG was attached to the muscles around the shoulder of the subjects during the execution of aforementioned movement to examine the changes in the level of muscular activation at the time of abduction of the shoulder in accordance with each of the breathings.

\section{Measurements and Statistical analysis}

Wireless EMG equipment (TeleMyo 2400T, Noraxon Co., Arizona, USA) was used to measure the level of 
Table 3. The maximum voluntary contraction value of inhalation and exhalation in Pilates breathing

\begin{tabular}{ccc}
\hline & Breathing & $\% \mathrm{MVC}$ \\
\hline \multirow{2}{*}{ InC } & Inhalation & $12.23 \pm 1.27$ \\
& Exhalation & $15.80 \pm 1.79$ \\
IO & Inhalation & $6.40 \pm 1.26$ \\
& Exhalation & $8.58 \pm 1.33$ \\
EO & Inhalation & $11.95 \pm 1.24$ \\
& Exhalation & $19.94 \pm 2.12$ \\
TrA & Inhalation & $9.96 \pm 1.45$ \\
& Exhalation & $12.99 \pm 2.01$ \\
\hline
\end{tabular}

Values are presented as mean \pm standard deviation.

InC : Intercostal, IO: internal oblique, EO: external oblique, TrA : transvers abdominis.

muscular activation and MyoResearch XP, Master Edition

of Noraxon was used for data analysis. Small surface electrodes with a diameter of $30 \mathrm{~mm}$ (Kendall, USA) were used and the electrodes were placed with the interval of $2 \mathrm{~cm}$ between them. The task of fixating the surface electrodes was executed by making marks using a ballpoint pen on the area of attachment on the muscle to be measured for EMG analysis. At this time, the skin surface was sufficiently cleansed with rubbing alcohol to remove foreign matters and the skin was rubbed with sandpaper to reduce the electric resistance of the skin's surface before the electrodes are attached. In order to examine the level of muscular activation of the muscles around the shoulder in accordance with the execution of the movements of the trunk muscles and abduction of the shoulder to use biofeedback, the maximum voluntary contraction (MVC) of all the subjects prior to the measurement was measured. The location of the attachment of surface EMG of each of the muscles and the posture of measurement are given below (Table 3). All the statistical processing including the calculation of average and standard deviation were made by using SPSS 19.0 and comparative analysis was made by using a paired t-test. All the levels of statistical significance were set at $\mathrm{p}<.05$.

\section{Results}

As the results of the measurement of the activation of the trunk muscles displayed at the time of Pilates breathing, which is provided as biofeedback, muscular activations of $\mathrm{InC}, \mathrm{TrA}, \mathrm{EO}$ and $\mathrm{IO}$ were found to be $12.23 \pm 1.27 \%$, $9.96 \pm 1.45 \%, 11.95 \pm 1.24 \%$ and $6.40 \pm 1.26 \%$, respectively, at the time of inhaling with the highest value measured at the InC. Moreover, muscular activations of the InC, TrA, IO and EO were found to be $15.80 \pm 1.27 \%, 12.99 \pm 2.01 \%$, $8.58 \pm 1.33 \%$ and $19.94 \pm 2.1 \%$, respectively, at the time of exhaling with the highest value measured at the EO (Table 3). Changes in the level of activation of the muscles around the shoulder during abduction of the shoulder executed at the time of Pilates breathing and regular breathing by using biofeedback provided with the above values as the references were as follows. The levels of activation of SCM muscle were measured to be $2.46 \pm \pm 2.01 \%$ and $3.71 \pm 2.27 \%$ at the time of inhaling while supinating the shoulder during regular breathing and Pilates breathing, respectively, while the levels of activation of SCM muscles were measured to be $2.25 \pm 1.85 \%$ and $3.54 \pm 2.32 \%$, respectively, at the time of exhaling. The levels of activation of UT muscle were measured to be $14.56 \pm 8.95 \%$ and $10.48 \pm 7.17 \%$ at the time of inhaling while supinating the shoulder during regular 
Table 4. Pilates breathing and general breathing through shoulder abduction muscle activity

(\%MVC)

\begin{tabular}{|c|c|c|c|}
\hline & Type & Breathing & Mean \pm SD \\
\hline \multirow{4}{*}{ SCM } & \multirow{2}{*}{$\mathrm{PB}^{*}$} & Inhalation & $2.46 \pm 2.01$ \\
\hline & & Exhalation & $2.25 \pm 1.85$ \\
\hline & \multirow{2}{*}{$\mathrm{RB}$} & Inhalation & $3.71 \pm 2.27$ \\
\hline & & Exhalation & $3.54 \pm 2.32$ \\
\hline \multirow{4}{*}{ UT } & \multirow{2}{*}{$\mathrm{PB}^{*}$} & Inhalation & $10.48 \pm 7.17$ \\
\hline & & Exhalation & $11.56 \pm 7.10$ \\
\hline & \multirow{2}{*}{$\mathrm{RB}$} & Inhalation & $14.56 \pm 8.95$ \\
\hline & & Exhalation & $17.54 \pm 9.57$ \\
\hline \multirow{4}{*}{ DEL } & \multirow{2}{*}{$\mathrm{PB}^{*}$} & Inhalation & $12.88 \pm 5.80$ \\
\hline & & Exhalation & $15.14 \pm 5.49$ \\
\hline & \multirow{2}{*}{$\mathrm{RB}$} & Inhalation & $13.97 \pm 6.13$ \\
\hline & & Exhalation & $19.49 \pm 9.18$ \\
\hline
\end{tabular}

Values are presented as mean \pm standard deviation.

SCM : Ssternocleidomastoid, UT : Upper Trapezius, Del : Deltoid, PB : Pilates Breathing, RB : Regular Breathing. $* \mathrm{p}<.05$

breathing and Pilates breathing, respectively, while the levels of activation at the time of exhaling were found to be $17.54 \pm 9.57 \%$ and $11.56 \pm 7.10 \%$, respectively, thereby displaying statistically significant difference. The levels of activation of the Del muscle were measured to be $13.97 \pm 6.13 \%$ and $12.88 \pm 5.80 \%$ at the time of inhaling while supinating the shoulder during regular breathing and Pilates breathing, respectively, while the levels of activation at the time of exhaling were found to be $19.49 \pm 9.18 \%$ and $15.14 \pm 5.49 \%$, respectively, thereby illustrating that the level of muscular activation during Pilates breathing is lower than that during regular breathing with statistical significance (Table 4).

\section{Discussion}

This Study compared the level of activation of the muscles around the shoulder at the time of abduction by using Pilates breathing and regular breathing. It was aimed at providing the activation of the $\mathrm{InC}$ and abdominal muscle displayed at the time of Pilates breathing as biofeedback for accurate application of Pilates breathing. Pilates breathing induces the activation of the $\mathrm{InC}$ at the time of inhaling and the activation of the entire abdominal muscles at the time of exhaling (Pilates and Miller, 1960). It is reported that such Pilates breathing makes the movement of the limbs flexible and supple by increasing stability by connecting the ribs, abdomen and pelvic base, and through coordination of the trunk muscles (Latey, 2002). During inhalation in Pilates breathing, muscle activities of $\mathrm{InC}, \mathrm{EO}, \mathrm{TrA}$, and $\mathrm{IO}$ were $12.23 \pm 1.27 \%$, $11.95 \pm 1.24 \%, 9.96 \pm 1.45 \%$, and $6.40 \pm 1.26 \%$ respectively. Moreover, During exhalation in Pilates breathing, muscle activities of InC, EO, TrA, and IO were 19.94 $\pm 2.12 \%$, $15.80 \pm 1.79 \%, 12.99 \pm 2.01 \%$ and $8.58 \pm 1.33 \%$, respectively. As a result, the activity of the intercostal muscles was highest during inhalation. And the rate of increase in activity was the lowest in the intercostal muscles during exhalation. These results were in concordance with the findings of the preceding research (Ishida and Watanabe, 2012) that the $\mathrm{InC}$ is important at the time of inhaling 
and that the activations of the TrA, EO and IO increase at the time of exhaling in order to achieve stability of the trunk during Pilates breathing. Therefore, quantification of Pilates breathing was obtained through the results of this Study, which was then provided as biofeedback of Pilates breathing at the time of abduction of the shoulder. When abduction of the shoulder is executed through Pilates breathing, the level of muscular activation of the UT muscle at the time of exhaling of Pilates breathing was 11.56 $\pm 7.10 \%$ while that of the UT muscle at the time of exhaling of regular breathing was $17.54 \pm 9.57 \%$. It can be seen that the level of muscular activation at the time of Pilates breathing is substantially lower than that at the time of regular breathing. Moreover, the levels of activation of the Del muscle were also lowered with the values of $12.88 \pm 5.80 \%$ at the time of inhaling and $15.14 \pm 5.49 \%$ at the time of exhaling during Pilates breathing. That is, at the time of abduction of the shoulder through Pilates breathing, the levels of activation of the agonistic muscles and accessory muscles are lower than the levels of muscular activation at the time of abduction of the shoulders through regular breathing. It is thought that the levels of activation of the UT muscle and Del muscle are lowered due to the stability of the trunk provided at the time of Pilates breathing. Therefore, it is deemed that the Pilates breathing not only provides stability of the trunk but also is effective in achieving efficiency of the use of body energy by inducing functional movement of the limbs, simultaneously. However, the limitation of this Study include the higher levels of activation of the SCM muscle at the time of inhalation and at the time of exhalation of Pilates breathing than those of the regular breathing. This is deemed to be the results of slight compensation since Pilates breathing was implemented on subjects who are still not very familiar with and insufficient in their techniques for Pilates breathing. Accordingly, it appears that more reliable and valid information could be obtained in future researches if the comparison of the level of muscular activation generated at the time of movement by using Pilates breathing is made for more diversified movements.

\section{Conclusion}

In conclusion, the results could be interpreted as indicating that the muscle activities of upper trapezius and deltoid muscle were decreased based on pilates breathing more than those on regular breathing.

\section{References}

Anderson BD, Spector A. Introduction to pilates-based rehabilitation. Orthopaedic Physical Therapy Clinics of North America. 2000;9:395-410

Akuthota V, Nadler SF. Core strengthening. Arch Phys Med Rehabil. 2004;85(3):86-92.

Alexandre, Camila, Silva, et al. The Pilates breathing technique increases the electromyographic amplitude level of the deep abdominal muscles in untrained people. Journal of Bodywork and Movement Therapies. 2015;19:57-61.

Atılgan E, Aytar A, Çağlar A, et al. The effects of Clinical Pilates exercises on patients with shoulder pain: A randomised clinical trial. Journal of Bodywork and Movement Therapies. 2017;21(4):847-51

Barbosa AWC, Guedes CA, Bonifácio DN, et al. The Pilates breathing technique increases the electromyographic amplitude level of the deep abdominal muscles in untrained people. Journal of Bodywork and Movement Therapies. 2015;19:57-61.

Dunleavy K, Kava K, Goldberg A, et al. Comparative effectiveness of Pilates and yoga group exercise interventions for chronic mechanical neck pain: quasi-randomised parallel controlled study. Physiotherapy. 2016;102(3):236-42. 
De Siqueira Rodrigues BG, Cader SA, Torres NVOB, et al. Pilates method in personal autonomy, static balance and quality of life of elderly females. Journal of Bodywork and Movement Therapies. 2010;14:195-202.

Endleman I, Critchley D.J. Transverse abdominis and obliquus internus activity during Pilates exercises: measurement with ultrasound scanning. Arch Phys Med Rehabil. 2008;89:2205-12.

Friedman P, Eisen G, Miller WJ. The Pilates Method of Physical and Mental Conditioning Doubleday and Company. New York. 1980.

Gallagher S, Kryzanowska R, The Pilates Method of Body Conditioning Bain Bridge Books, Philadelphia. 1999.

Ishida, Hiroshi, Watanabe. "Influence of inward pressure of the transducer on lateral abdominal muscle thickness during ultrasound imaging." J Orthop Sports Phys Ther. 2012;42(9):815-8.

Ishida $\mathrm{H}$, Hirose $\mathrm{R}$, Watanabe $\mathrm{S}$. Comparison of changes in the contraction of the lateral abdominal muscles between the abdominal drawing-in maneuver and breathe held at the maximum expiratory level. Manual Therapy. 2012;17:427-31.

Keays KS, Harris SR, Lucyshyn JM, et al. Effects of Pilates exercises on shoulder range of motion, pain, mood, and upper-extremity function in women living with breast cancer: a pilot study. Phys Ther. 2008; 88:494-510.

Kim K. Effect of diaphragmatic breathing exercise on activation of lumbar paraspinal muscles of healthy people. J Korean Soc Phys Med. 2006;1(1):59-66.

Kwon HY, Moon HJ, Kim MJ. The Effects of pilates based breathing on changes in the thicknesses of the abdominal muscles. J Korean Soc Phys Med. 2016;11(3):59-63.

Levine B, Kaplanek B, Scafura D, et al. Rehabilitation after total hip and knee arthroplasty: a new regimen using Pilates training. Bulletin of the NYU Hospital for Joint Diseases. 2007;65:120.
Latey, P. Updating the principles of the pilates method: part1. Journal of Bodywork and Movement Therapies. 2001;5(4):275-82.

Latey, P. Updating the principles of the pilates method: part2. Journal of Bodywork and Movement Therapies. 2002;(2):94-101.

La Touche R, Escalante K, Linares MT. Treating non-specific chronic low back pain through the Pilates Method. Journal of Bodywork and Movement Therapies. 2008;12:364-70.

Marques, N. R., Morcelli, M. H., Hallal, C. Z., Gonçalves, M. EMG activity of trunk stabilizer muscles during centering principle of pilates method. Journal of Bodywork and Movement therapies. 2013;17(2): 185-91.

Mateus Beltrame Giacomini, Antônio Marcos Vargas da Silva, Laura Menezes Weber, Mariane Borba Monteiro, The Pilates Method increases respiratory muscle strength and performance as well as abdominal muscle thickness. Journal of Bodywork and Movement Therapies. 2016;20:258-64.

Merrick J, Axen K. Inspiratory muscle function following abdominal weight exercises in healthy subjects. Phys Ther. 1981;61:651-6.

Miyamoto, Gisela C, Leonardo OP Costa, et al. Efficacy of the Pilates method for pain and disability in patients with chronic nonspecific low back pain: a systematic review with meta-analysis. Brazilian Journal of Physical Therapy. 2013;17(6):517-32.

Panjabi MM. The stabilizing system of the spine, part 1: function, dysfunction, adaptation, and enhancement. J Spinal Disord. 1992;5(4):383-9.

Park MC, Goo BO, Bae SS. The review of breathing pattern training for the spinal stabilization. J Korean Soc Phys Med. 2007;2(2):173-82.

Penelope L: Updating the principles of the Pilates method Part 2. Journal of Bodywork and Movement Therapies, 2002;6:94-101. 
Pilates, JH. \& Miller, WJ. Pilates' Return to Life through Contrology. Presentation Dynamics Incorporated. 1998.

Posadzki P, Lizis P, Hagner-Derengowska M. Pilates for low back pain: a systematic review. Complementary
Therapies in Clinical Practice. 2011;17(2):85-9.

Siler B. The Pilates Body: The ultimate at home guide to strengthening, lengthening, and toning your bodywithout machines. Broadway. 2000. 